\title{
Study of details and features of the pre-schoolers uniforms of Chandigarh schools
}

\author{
Lalita Rani and Jetinder Sohi
}

Received: 08.12.2017; Revised: 07.04.2018; Accepted: 26.04.2018

See end of the paper for authors' affiliations Lalita Rani

Govt. Home Science College, Chandigarh (U.T.) India
ABSTRACT : A study on the uniforms of pre-school children of Chandigarh schools was taken up in order to find out the suitability of uniforms in terms of style, designs, details, colours and material; features required in the uniforms and opinions of mothers regarding the school uniforms of pre schoolers. All the preschool children in the study were in the age group of three to five years and were studying in the pre nursery, nursery or kindergarten class. Styles of summer uniforms for boys was almost same in all schools i.e. knicker with half sleeves shirt or Tshirt, there was however a slightly difference in the style of knicker as two schools had knicker with a bib. All schools had a belt but three schools had tie in uniforms. Commonly seen styles of uniforms for girls were- five schools had tunic/pleated skirt/pinafore and half sleeves shirt/Tshirt with belts, frocks and knicker with elasticated waistband with shirt/ T-T-shirt. The winter uniform was same for boys and girls in eleven schools. It was trouser and shirt with sweater, tie and jacket for boys, while girls had shirt, skirt with leggings, sweater, tie and jacket as their winter uniform. Five schools had tracksuits. Material of uniform of different schools was almost same i.e. terycot for shirts and trousers and acrylic for sweaters. Tracksuit and T-shirts were in hosiery material. Socks, belts and ties were of synthetic material. Black shoes were of leather and P.T. shoes were of canvas material.

KEY WORDS: Details, Features, Suitability, Pre-schoolers, Uniforms

- HOW TO CITE THIS PAPER : Rani, Lalita and Sohi, Jetinder (2018). Study of details and features of the pre-schoolers uniforms of Chandigarh schools. Asian J. Home Sci., 13 (1) : 225-230, DOI: 10.15740/ HAS/AJHS/13.1/225-230. Copyright@ 2018: Hind Agri-Horticultural Society. 